\title{
Assessing and Reinvigorating a Teaching Assistant Support Program: The Intersections of Institutional, Regional, and National Needs for Preparing Future Faculty
}

\section{Kathleen S. Smith}

University of Georgis

This chapter discusses an assessment of an 11-year old teaching assistant (TA) support program at a Research I institution. The TA support program was developed on the premise that professional preparation of teachers includes fundamental teaching competencies or skills that can be identified, developed, and evaluated (Simpson \& Smith, 1993; Smith \& Simpson, 1995). The purpose of this longitudinal study was to identify and enbance the institutional enabling factors that belp graduate teaching and laboratory assistants in performing their duties and in using their graduate experience to prepare for careers at a variety of academic institutions.

\section{INTRODUCTION}

Tnstitutions of higher education invest heavily in the undergraduate teaching Ienvironment, in graduate education, and in the identification of faculty who will further the institutional mission. These factors make it imperative to support the successful development of graduate students as instructors in the undergraduate classroom and as future faculty. In addition, graduate students are a tremendous source of intellectual inspiration for undergraduates and 
constitute a renewable resource for the future of higher education. The teaching assistant (TA) support program at this Research I institution was developed based on the concept that professional preparation of teachers includes fundamental teaching competencies which can be identified, agreed upon, and evaluated (Simpson \& Smith, 1993; Smith \& Simpson, 1995). Effective graduate preparation should include many opportunities to develop these teaching competencies as these are the skills new faculty will have to demonstrate to be successful teacher-scholars. This chapter describes a longitudinal study of a cohort of outstanding graduate students and their graduate teaching experiences as they prepared for and moved into faculty roles. Pivotal events related to the development of teaching competencies shape graduate students' professional development and allow them to be knowledgeable and successful participants in the academic culture of their institution. The researcher identified those pivotal events that contributed to or detracted from the successful preparation of the participants in this study for their faculty teaching responsibilities. The rationale for this ongoing longitudinal study is to identify and support the institutional enabling factors that contribute positive experiences while reducing the events that seem to detract from the development of a professional approach to the scholarship of teaching.

\section{BACKGROUND}

In the early 1990s, the investigator in this study sought the expert opinion of academic staff who were involved in faculty and teaching assistant support at Carnegie I or II institutions to identify and validate teaching competencies for graduate teaching assistants and faculty (Simpson \& Smith, 1993; Smith \& Simpson, 1995). National leaders involved in the professional preparation of teaching assistants and faculty were able to validate competencies or skills as they applied to teaching roles. These competencies were then considered in the context of professional preparation for graduate teaching assistants at a Research I institution. Each of the competencies was assigned to six fundamental skill areas including scholastic, planning, management, presentation/communication, evaluation/feedback, and interpersonal skills. The development of these competencies or skills became the foundation of professional preparation for graduate teaching assistants at this Rescarch I institution (Figure 8.1). Graduate students who have achieved a certain level of teaching skill or competency are nominated by their departments each year for several teaching awards given by the institution. All teaching award recipients who are preparing for faculty carcers are invited to apply for the TA mentor program, a preparing future faculty program. Each year, ten to 15 TA 
mentors representing disciplines from across campus are selected for the TA mentor program. These future faculty work with the teaching support office in preparing for their faculty careers and in increasing departmental opportunities for all TAs (Smith, 1993). The investigator has documented the professional development and career path of TA mentors since 1990 as well as the impact of departmental and institutional support. Currently, there are over 100 present and former TA mentors included in the database. The rationale for following the professional preparation of these outstanding graduate students and future faculty was to document their successful use of resources and strategies in becoming competent instructors, in obtaining faculty positions, and in becoming knowledgeable participants of the culture of their academic institutions, and then to use this information to provide better support for all TAs at this institution. TA mentors participate in a yearlong mentoring experience that includes group discussions on teaching, individual mentoring by faculty members, and mentoring by and for TA peers. In addition, past and present TA mentors are able to participate in a private listserv discussion on teaching (Smith, 1993). This network of teaching support from TA mentors who have moved to other institutions is a unique strength of this TA support effort. These past TA mentors continue to mentor new TAs at this institution on the reality of faculty positions at a variety of institutions. They also continue to give a cross-discipline perspective on the teaching and learning enterprise and reflect on how their graduate teaching experience is currently affecting their career. As new faculty members, they also frequently mentor TAs at their new institution, often by sharing the TA mentor list discussions.

\section{MeTHODOLOGY}

This is a qualitative, multicase study (Merriam, 1988). The pattern of behavjor we were interested in documenting is how graduate teaching assistants successfully use their graduate experience to prepare for academic careers. Our goal was to generate theory that accounts for a pattern of behavior that is relevant and problematic for those involved (Strauss, 1987) and to identify the events that contributed or detracted from successful teaching preparation. With the constant comparative method to develop grounded theory as outlined by Glaser and Strauss (1967), we continually asked our respondents to clarify or enlarge upon our interpretation of the data. Over a ten-year period, we analyzed the intersections of institutional, regional, and national needs for well-prepared instructors and our respondents' use of the resources and support services on our campus. The assessment of how graduate students became 
outstanding teachers and knowledgeable faculty members helped to expand and reinvigorate our TA support structure.

\section{Data Analysis and Interpretation Techniques}

At this point in the study, data collection and analysis has occurred simultaneously over a ten-year period and includes 96 former TA participants at 55 institutions of higher education in the United States. Phase I of the study occurs each year as the new TA mentor group participates in qualitative interviews (Spradley, 1979) and observations (Spradley, 1980) related to their teaching. The researcher transcribes and enters data from interviews, observations, group discussions on teaching, and from the listserv (TAMENTOR) into a computerized database manager. In addition, graduate experiences that seem to contribute or detract from their development as teacher-scholars are noted. We also track their job search to identify the factors which enabled them to successfully secure their first faculty position. These data are coded and categorized to identify patterns and roles that contribute to the TA experience and a smooth transition into faculty positions (Smith, in press).

The focus of the Phase II data collection is to determine what aspects of the graduate experience help participants, from a variety of backgrounds, successfully move into academic careers. Phase II of the study began in 1994 as members of the first cohort of the TA mentor study moved into their first faculty positions and began to use their graduate experience as the basis for a career. Data from Phase II participants comes from TAMENTOR listserv discussions, mailed questionnaires, and individual interviews. Participants on the TAMENTOR listserv discussion are able to compare perceptions and strategies and to verify our understanding of the data. Integrative diagrams are used from the early stages of the data collection to visualize and conceptualize data. We identified background, intervening, enabling, and outcome variables that affected the transition process in moving from a graduate teaching role to a faculty role (Smith \& Kalivoda, 1998).

In 1999, Phase III of the study began as the early TA Mentor cohorts completed the third-year review process or were put up for promotion. A questionnaire was mailed to 96 former TA mentors at 55 institutions of higher education in the United States and abroad. Of these 96, 52 are female, 44 are male, and 11 are minority or international participants. In this phase of the study, the participants identified the events in their graduate program that contributed to their professional development as teacher-scholars as wcll as the events that negatively influenced their professional growth. Response to the mailed survey totaled 42 . We followed up with those not responding to the 
initial survey with questions via the TAMENTOR listserv discussion. We coded and analyzed the insights of the 42 responding to the survey as well as the comments and responses from the 72 former $T A$ mentors currently active on the TAMENTOR listserv discussion (Smith, in press). This chapter details three representative cases to illustrate the process of successful graduate teacher preparation for a career in higher education.

\section{Case Study Types}

This is a multicase study that seeks to build abstractions across cases to understand the process of successful graduate teaching development leading to an academic career. The following individual cases provide a compelling interpretation of how graduate students use the assistantship to become competent instructors and to navigate academic cultures eventually leading to an academic career.

\section{Case 1: Kurt Rose}

When Kurt Rose was several years into his doctoral program he already knew he preferred to become a faculty member at a four-year college with a master's program. He had a strong interest in teaching but also valued meaningful research. During his doctoral program, he was teacher of record for eight sections of three different 500 level classes with an enrollment of about 50 students each. His department had no formal support for TAs to develop their teaching, although a number of outstanding teaching faculty mentors were available to answer questions.

Kurt took the required teaching support seminar offered by the faculty development office where the teaching competencies and skills were addressed. In the seminar, he also became familiar with technology opportunities and support available to faculty and TAs. He sought teaching support from his departmental faculty and the central teaching support program and developed his teaching to the point that he won an outstanding teaching award from the university. As an award-winning TA, Kurt was selected for the TA mentor program. Kurt's teaching goal was to expand his use of technology and encourage more interactive learning.

As a TA mentor, Kurt interacted with other award-winning TAs and faculty from other disciplines in using technology and discussing the scholarship of reaching in preparing for faculty roles. During the TA mentor year, he learned how to document his graduate experience and how to interview and identify a good institutional match for his professional goals. He entered a very tough job market with more than 300 hundred applicants vying for 50 
positions in the United States and abroad. Based on his strong teaching credentials, he landed a one-year international teaching position. During the year, he expanded his teaching and research to include an international perspecrive and had time to focus on various aspects of his professional scholarship. During his time abroad, he was an active participant on the TAMENTOR listserv with past and present TA mentors.

The next year he accepted a job offer at a four-year state university in the United States with a strong emphasis on teaching. While maintaining his teaching excellence, he also concentrated on research publications in this second faculty position. As a result of his enhanced professional experiences he was offered a position at a prestigious private university and a state university. He accepted the offer at the state university knowing it had a major research focus. However, within a year, he made a decision to return to his second position at the four-year university because its teaching focus meshed better with his professional and personal goals. He was welcomed back by that institution.

\section{Case 2: Ann Green}

Ann Green aspired to become a faculty member at a small teaching college as she began her doctoral program. Her goal was to develop alternate teaching strategies that emphasized student thinking. However, she felt her first teaching experience was less than she had hoped for in terms of student investment in the material and in her own ability to assess student learning. Her department had a structured teaching support program consisting of a resource room established by a former TA mentor and a semester-long teaching support seminar conducted by an award-winning TA under the supervision of the department head.

Ann worked diligently for several years on becoming a more effective teacher. Eventually, she developed her teaching to the point she won a teaching award from the institution. As an award-winning TA, she was selected for the TA mentor program where she interacted with award-winning TAs and faculty from other disciplines in discussing the scholarship of teaching and in preparing for faculty roles. As a TA mentor, she was encouraged to present at teaching conferences and to develop her teaching scholarship. The year following the TA mentor program, Ann was awarded a teaching assistantship to lead the departmental teaching support seminar for her department.

In this mentoring leadership position, she worked with new TAs in the department as they developed and documented their graduate teaching experiences. Ann won a national teaching excellence award based on the teaching portfolio she had developed in the TA mentor program. She received funding 
to travel to the meeting from the institution where she met leaders in her field in both teaching and research. Upon graduation, she was sought after by a variety of institutions. She decided to accept a teaching postdoctoral position at a university where she would teach two classes a semester and have time to further develop her teaching and research. During that time she attended teaching conferences and worked with undergraduates in the research setting. She also participated in a listserv discussion on teaching issues with over 100 former TA mentors across the United States and abroad. After a very successful two years in this position, she wrote a grant that enabled her to accept a prestigious three-year research post-doctoral position. Ann's professional goals have developed to include a broad spectrum of academic roles including teaching and research opportunities. She feels her discipline job market makes these post-doctoral positions crucial in securing the kind of position she now feels she would like to pursue.

\section{Case 3: Pam Cane}

Pam Cane's long-range career plans were to work at a research institution upon receiving her doctorate. She was in a professional school that had no formal support for teaching. However, she had a very supportive major professor and a strong graduate student cohort. Institutional policy required her to take the central teaching support seminar offered by the faculty development office. She was also very proactive in seeking out teaching support from departmental faculty and the faculty development office, including funding to improve courses. In addition, she offered to help with the revision of the TA handbook that made her more aware of good pedagogy and the teaching resources on campus.

During her graduate preparation she taught discussion sessions, independent classes in the evening classes division of her department, large lecture survey classes of over 200 students, and senior-level seminars. Her teaching evaluation averages consistently ranked above departmental and college averages. Eventually, she was awarded the outstanding teaching assistant award from the department and institution. As an award-winning TA she was selected for the TA mentor program where she interacted with other outstanding TAs, faculty, and teaching support staff.

During the year she was a TA mentor, she developed a teaching portfolio, increased peer mentoring efforts in her department, and discussed the scholarship of teaching related to the reality of the job market at diverse institutions. She went on to win the excellence in teaching award given to only five individuals per year. Following the TA mentor year, she entered the job mar- 
ket and was successful in getting numerous interviews and offers from a variety of institutions. She accepted a tenure-track position at a very prestigious Research I institution.

Pam continued to discuss the scholarship of teaching and the politics of academic life on the TAMENTOR listserv. She also shared many of these discussions with graduate students at her new institution. In her new faculty position, she received the senior class favorite faculty award and several course enhancement grants from the teaching support office. She was also an active researcher and published numerous articles and several book chapters as well as presented at discipline-related conferences both on her research and teaching. Within six years, Pam was promoted with tenure.

\section{Discussion}

The three cases exemplify the complexity of preparing graduate students from diverse disciplines for a variety of teaching assignments, career goals, and academic job markets. Nevertheless, there were pivotal events in their graduate preparation that contributed positively to their development as teacher-scholars. The most important event was that the institution required support for teaching. Neither Kurt nor Pam had formal support in their departments, but there was an institutional requirement that all TAs receive some support. They were asked to take the teaching support seminar offered by the central faculty development office which introduced them to a wide dimension of developmental opportunities.

Our data clearly indicated that some TAs were not getting any teaching support except in the required orientation and classes. Many new graduate students do not even know the questions to ask or the process to follow to improve teaching so required teaching support makes the process easier. All three of these TAs also had many opportunities to teach and gradually accepted more and more responsibility for teaching until they were teacher of record with full responsibility. The institution also provided a mechanism for them to be recognized and rewarded for their successful teaching. This was identified as an extremely important pivotal event because it was public recognition and permission for them to be identified for their teaching efforts. This recognition also led to many other opportunities including the TA mentor program, assistantships associated with departmental teaching support efforts, and national awards and opportunities to attend teaching conferences.

Each of these TAs became leaders in their departments in mentoring new TAs and in discussing the scholarship of teaching. They have continued this mentoring leadership on the TAMENTOR listserv and in their new depart- 
ments. In the TA mentor year, they developed a clear sense of themselves as teacher-scholars; they learned how to document their graduate experiences and to identify their professional goals and values. They were also introduced to the concept of career stages when it may be necessary to focus for a while on one area and then switch gears to focus on other areas. In addition, they learned to realistically assess the job market in their field and set goals that would eventually get them the kind of academic position that meshed with their talents and interests.

We chose to track the graduate preparation and career path of this particular group of graduate students because they had been outstanding graduate students in terms of successful teaching, the completion of meaningful research and doctoral programs, and had successfully navigated a variety of academic job markets to secure academic positions that fit their particular goals and talents. It was our belief that if we could understand the process by which these students appeared to benefit from their graduate preparation for an academic career, we could strengthen our support structure for all graduate students at this institution. Our ten-year survey of the TA mentors confirmed the importance of the teaching skills and competencies upon which we had built our teaching support program. It also revealed that there was a set of pivotal events which contributed to graduate teaching preparation for a career in higher education as well as persistent events in some departments which seemed to hinder a graduate student's ability to develop the scholarship of teaching (Figure 8.1).

\section{FIGURE 8.1}

\section{Pivotal Events in Graduate Teacher Preparation for a Faculty Career}

\section{Scholastic Skills}

- Recognize and accept teaching as a fundamental and challenging dimension of scholarship.

- Demonstrate mastery of subject matter.

- Advise students of career opportunities in the discipline or profession.

- Demonstrate relationships between the course and the broader liberal education curriculum.

- Enhance motivation of students by demonstrating relevance to future needs and goals of students.

\section{Positive Events Contribute to Success}

- Introduced to teaching as scholarship 
- Teaching opportunities in department-developmental and variety of classes

- Opportunity to attend teaching conferences and publish in teaching journals

- Taking the initiative to improve teaching

- Official recognition-opportunity for teaching awards

- Cross campus perspective of teaching from teaching support class, TA mentors

- Sense of community-being accepted as a peer by colleagues

\section{Negative Events Detract from Success}

- Little support of teaching expressed in department

- Little interest in the developmental needs of undergraduates

- Reluctance of department to recognize outstanding teaching by nominating TAs for teaching awards

- Lack of community related to the scholarship of teaching

\section{Planning Skills}

- Select course material suited to the background, ability level, and interests of students.

- Match varying teaching methods with specific instructional objectives.

- Present material that is sequenced and paced appropriately for learners.

- Promote individual involvement of students through learner-centered teaching methods.

- Encourage cooperation and collaboration among students.

- Enhance motivation of students by demonstrating relevance to future needs and goals of students.

\section{Positive Events Contribute to Success}

- Feedback on teaching-departmental, student, peer

- Opportunity to revise and develop new courses

- Exposure to learning styles and student developmental needs

- Exposure to multidisciplinary approaches to teaching

- Institutional or departmental support structure-credit classes, resource room, individual consultation, mentoring

\section{Negative Events Detract from Success}

- No opportunity to develop teaching-laboratory teachers or same class year after year with focus directed by department 
- Negative message on undergraduate abilities

- Lack of faculty understanding of undergraduate cognitive needs

\section{Management Skills}

- Communicate important departmental policies that relate to the goals of the course.

- Manage administrative responsibilities such as ordering books, handling withdrawals, and complying with other departmental requirements.

- Communicate and manage appropriate expectations for achievement in the course.

- Communicate and implement important safety measures in the classroom.

- Deal appropriately with matters of discipline, academic honesty, and legal information.

- Manage the learning environment so that optimum learning will result.

\section{Positive Events Contribute to Success}

- Strong departmental teaching support structure

- Opportunity and encouragement for improving a course

- Well-publicized institutional guidelines for teaching

- Development of priorities-clear goals in professional and personal life

- Learning time-management skills

- Leadership in mentoring other TAs

\section{Negative Events Detract from Success}

- Lack of departmental communication about teaching and teaching resources

- Negative departmental message on undergraduate abilities

- Personal responsibilities-balance of professional and personal life

- TAing for poorly organized courses 


\section{Presentation and Communication Skills}

- Communicate effectively in both written and oral formats in English.

- Lead class discussions that stimulate learning and enhance the goals of the course.

- Use technology to enhance learning.

- Promote individual involvement of students through learner-centered teaching methods.

- Encourage cooperation and collaboration among students.

- Enhance motivation of students by demonstrating relevance to future needs and goals of students.

\section{Positive Events Contribute to Success}

- Developmental support for presentations and writing

- Technology support to improve pedagogy and learning

- Introduction to other possibilities for teaching

- Modeling from professors and peers and from teaching support seminar and TA mentor program

\section{Negative Events Detract from Success}

- No departmental feedback on teaching

- No access to technology in department

- Overzealous use of technology

- Classes too large to promote interaction among students

\section{Evaluation and Feedback Skills}

- Construct valid and reliable tests and administer fairly other evaluation measures.

- Provide helpful feedback to students in a variety of ways.

- Develop a reflective approach to teaching through collecting feedback and continually modifying instructional approaches.

\section{Positive Events Contribute to Success}

- Opportunity for student cvaluations

- Learning classroom assessment strategies

- Learning how to reflect on teaching and document successes

- Guidance in kinds of feedback students find useful

- Culture of respect for students and for the TA role 


\section{Negative Events Detract from Success}

- Having to respond to someone else's exam procedure with little TA input

- Little training in constructing good exams

- No mechanism for TA feedback

- Message from faculty to ignore student evaluations

\section{Interpersonal Skills}

- Enhance motivation of students through personal enthusiasm for the subject.

- Exhibit respect and understanding for all students.

- Demonstrate a general belief that all students are capable of learning.

- Deal appropriately with issues that relate to various aspects of diversity.

- Enhance motivation of students by demonstrating relevance to future needs and goals of students.

\section{Positive Events Contribute to Success}

- Finding pleasure in a student's understanding of a difficult concept

- Knowing that, long term, efforts in teaching would outdistance efforts in research in terms of people impact

- Understanding that students learn in different ways

- Acknowledging multicultural issues

- Multidisciplinary interactions with TA mentors

\section{Negative Events Detract from Success}

- Departmental weed out course mentality

- Little departmental understanding of how students learn and how to provide learning support

- Lack of leadership opportunities in teaching

Smith, K. S. (2001, Fall). The Journal of Graduate Teaching Assistant Development, Vol. 8, No. 3, Stillwater, OK: New Forums Press

The pattern of behavior we were interested in documenting is how graduate teaching assistants successfully use their graduate experience to prepare for academic careers. It is evident that many of our respondents have made the transition into their academic roles because of the confidence they developed 
as graduate students in their teaching ability. Data from the longitudinal study identified the developmental aspect of the TA support program as the key factor in their successful preparation for an academic position. Although many also went on to be outstanding researchers, they acknowledged that having their teaching well in hand made it possible to concentrate on meaningful research. Those who had prepared for the third-year review process and tenure did so with ease because of the practice they had as graduate students in documenting their teaching and in creating a teaching or professional portfolio.

A significant finding of this study was the level of contentment among those who were not in tenure-track positions. Some are in rewarding postdoctoral positions that are further preparing them for the kind of faculty position they would eventually like to secure. Others have chosen nontenure-track positions, while several have moved from tenured positions to nontenured positions because these positions meshed better with their professional goals. They credit their graduate school teaching experiences with helping to make these important decisions and with easing this transition. With years of teaching experience documented in a professional portfolio, they came into their new positions recognized as teacher-scholars. Being knowledgeable teacher-scholars helped them to quickly ascertain the expectations of their new institution, at least in the teaching arena. Those who had extensive practice in developing courses and in teaching a variety of courses could more easily step into a new course while balancing other institutional expectations. Having also developed a reflective approach to teaching improvement, they actively sought peer feedback on their new roles and in some cases established strong mentoring relationships. Even without formal feedback mechanisms, these new faculty were able to seek out feedback on how they were doing as they moved through the first several years of academic positions.

A significant characteristic of the participants in this study was the entrepreneurial approach they took to managing their careers. They sought out and took advantage of teaching support as graduate students and continued to do so as new faculty.

\section{Conclusion}

The intersections of institutional teaching needs and regional and national needs for preparing future faculty seemed to mesh well for the cohort of graduate students in our study. They credited many of their successes to institutional policy that mandates teaching support that they were able to take advantage of or seek out on their own initiative. However, in assessing these pivotal events and the impact on graduate preparation for faculty positions, 
the data indicated that our TA support programming needed to reach a wider graduate student population. In some cases, TA mentors felt their graduate preparation was not shared by departmental peers. By expanding the TA mentor peer support effort in the departments and by expanding the teaching support seminar initiatives, we have begun to provide better support for all teaching and laboratory assistants. In 2000, we had 15 TA mentors setting up departmental seminars on everything from creating a teaching portfolio to using WebCT. In addition, we had over 300 graduate students enrolled in the semester-long departmental sections of our teaching support seminar. We accomplished this by providing partial assistantships to award winning TAs such as the TA mentors to help the faculty teacher of record develop a departmental teaching support seminar.

The departmental teaching seminar uses a graduate school course name, eliminating the need to have a new course approved. These efforts reduce the impression that teaching is not valued in a department. Departmental faculty are increasingly involved in very productive teaching discussions with their graduate students. These discussions influence departmental cultures and change the way individuals approach teaching and learning in the department. In addition, many departments are working to provide more teaching opportunities for their graduate students by allowing them to guest lecture and teach a variety of classes. The teaching support that is established by these seminars continues beyond the semester course because peers are readily available in the department to discuss teaching issues. In addition, we have added a very strong professional development component to these departmental efforts to address methods of professional documentation, the realities of the job market, and academic positions at nonresearch-oriented institutions.

This study has helped to reinvigorate our TA support program because it confirmed the skill and competency-based efforts we had in place were effective to meet institutional teaching needs. It also helped to identify areas of expansion and to garner the needed administrative support to provide stronger TA support structures in academic departments. We confirmed that teaching must be recognized and validated by the institution to optimize graduate student development as teacher-scholars. A teaching emphasis also reflects the reality of the job market (Menges, 1996; Western Interstate Commission for Higher Education, 1992). Graduate students continue to take the initiative to improve and refine their teaching as new faculty members if they have developed confidence and pride in their abilities to teach. Being knowledgeable participants in academic cultures made the transition into a faculty position 
smoother and provided a framework for successfully managing multiple dimensions of academic life.

\section{REFERENCES}

Glaser, B., \& Strauss, A. L. (1967). The discovery of grounded theory: Strategies for qualitative research. Chicago, IL: Aldine.

Menges, R. J. (1996). Experiences of newly hired faculty. In L. Richlin (Ed.), To improve the academy: Vol. 15. Resources for faculty, instructional, and organizational odevelopment (pp. 169-182), Stillwater, OK: New Forums Press.

Merriam, S. B. (1988). Case study research in education: A qualitative approach. San Francisco, CA: Jossey-Bass.

Simpson, R. D., \& Smith, K. S. (1993, Winter). Validating teaching competencies for graduate teaching assistants: A national study using the Delphi method. Innovative Higher Education, 18 (2), 133-146.

Smith, K. S. (1993, Spring). Investment in teaching: Mentoring for teaching assistants. The Journal of Graduate Teaching Assistant Development, I (1), 43-48.

Smith K. S. (in press). Pivotal events in graduate teacher preparation for a faculty career. The Journal of Graduate Teaching Assistant Development.

Smith K. S., \& Simpson R. D. (1995, Spring). Validating teaching competencies for faculty members in higher education: A national study using the Delphi method. Innovative Higher Education, 19(3), 223-233.

Smith, K. S., \& Kalivoda, P. L. (1998). Academic morphing: Teaching assistant to faculty member. In M. Kaplan \& D. Lieberman (Eds.), To Improve the Academy: Vol. 17. Resources for faculty instructional, and organizational development (pp. 85-102). Stillwater, OK: New Forums Press.

Spradley, J. P. (1979). The ethnographic interview. Chicago, IL: Holt, Rinehart and Winston.

Spradley, J. P. (1980). Participant observation. Chicago, IL: Holt, Rinehart and Winston.

Strauss, A. L. (1987). Qualitative analysis for social scientists. New York, NY: Cambridge University Press.

Western Interstate Commission for Higher Education. (1992). Bringing into focus the factors affecting faculty supply and demand: A primer for higher education and state policy makers. Boulder, CO: Author. 


\section{Contact:}

Kathleen S. Smith

Office of Instructional Support and Development

University of Georgia

Instructional Plaza

Athens, GA 30602

Voice (706) 542-1355

Fax (706) 542-6587

Email ktsmith@arches.uga.edu

Kathleen S. Smith is a Senior Academic Professional at the University of Georgia and has directed the TA Program for the Office of Instructional Support and Development since 1990. Dr. Smith's research and professional interests include the professional development of international TAs in the North American classroom, the institutional mechanisms to encourage globalization of the teaching and learning environment, and the professional development of future faculty. 